\title{
Iterative Joint Optimization of Transmit/Receive Frequency-Domain Equalization in Single Carrier Wireless Communication Systems
}

\author{
Xiaogeng Yuan, Osamu Muta and Yoshihiko Akaiwa \\ Kyushu University \\ Japan
}

\section{Introduction}

In recent years, high data-rate wireless transmission system such as IEEE802.16e has received increased attention. In such a system, inter-symbol interference (ISI) caused by frequency-selective fading severely degrades bit error rate (BER) performance. As a solution to overcome the effect of frequency-selective fading, Orthogonal Frequency Division Multiplexing (OFDM) has been considered. However, OFDM system has a problem that the Peak to Average Power Ratio (PAPR) becomes high as the number of sub-carriers increases. As an alternative method to solve the above problems, Single Carrier transmission with Frequency-Domain Equalization (SC-FDE) has been investigated. In this system, a low PAPR is achieved in contrast to the OFDM system and the received signal passing through frequency-selective fading channel is equalized with frequency-domain processing based on minimum mean square error (MMSE) criterion. Hence, BER performance of SC-FDE system without error correction coding is improved by obtaining the diversity effect.

In this study, as an alternative method to improve BER performance of SC-FDE system, we propose an iterative optimization method of transmit/receive frequency domain equalization (TR-FDE) based on MMSE criterion, where both transmit and receive FDE weights are iteratively determined with a recursive algorithm so as to minimize the mean square error at a virtual receiver.

\section{Proposed Iterative Optimization Method for TR-FDE}

Figure 1 shows a SC-FDE system considered in this study, where a frequency-domain equalizer is equipped at both transmitter and receiver. In the proposed method, optimum weight vectors for transmit and receive equalizers are obtained by minimizing mean square error including ISI and noise at the receiver side, i.e., the error signal is defined as the difference between transmit and receive signal vectors under the constraint of the constant average transmit power. This means that error signal at the receiver side should be estimated at the transmitter side. For this purpose, a virtual channel and receiver are equipped at the transmitter, where it is assumed that channel state information (CSI) is 
known to the transmitter. In this system, the transmitter needs to know channel state information (CSI) measured at the receiver side.

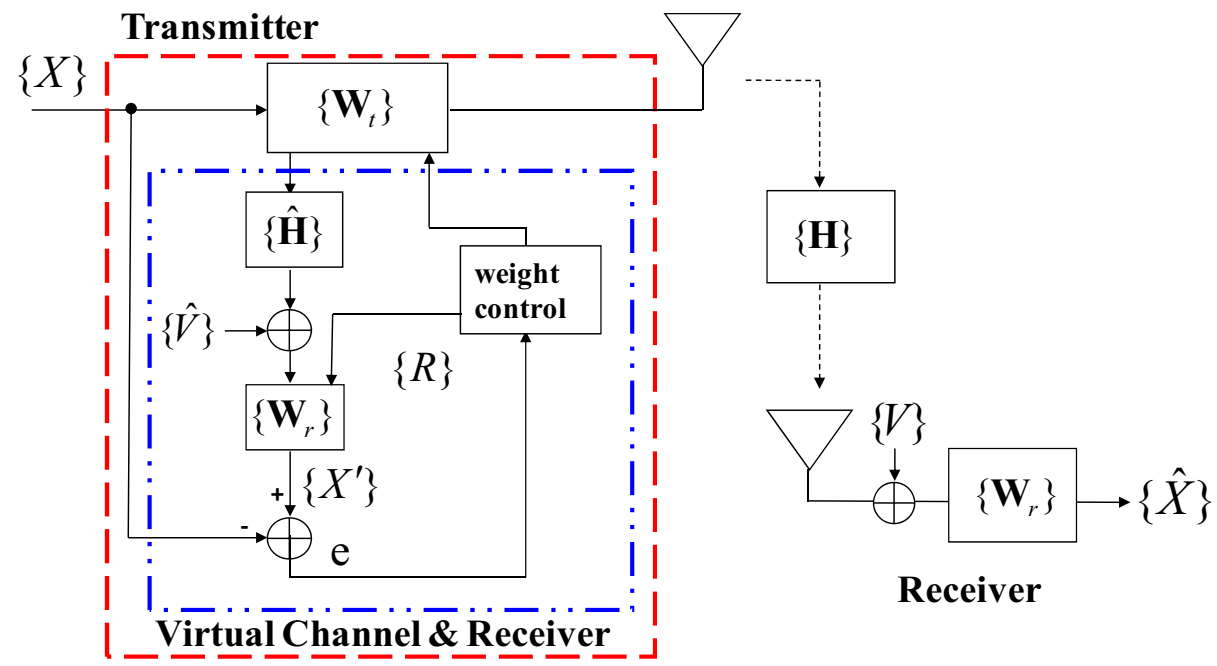

Fig. 1. Block diagram of the proposed system with transmit/receive frequency-domain equalization, where virtual channel and virtual receiver are equipped at the transmitter.

For simplicity of explanation, frequency-domain signal expressions are used in the following discussion. As shown in Figure 1, the received signal vector at the virtual receiver is expressed as

$$
\hat{\mathbf{R}}=\hat{\mathbf{H}}^{\mathrm{d}} \mathbf{W}_{\mathrm{t}}^{\mathrm{d}} \mathbf{X}+\hat{\mathbf{V}}
$$

where suffix $\mathrm{d}$ denotes diagonal matrix; $\hat{\mathbf{H}}^{\mathrm{d}}=\operatorname{diag}\{\hat{\mathbf{H}}\}$ and $\mathbf{W}_{\mathrm{t}}^{\mathrm{d}}=\operatorname{diag}\left\{\mathbf{W}_{\mathrm{t}}\right\}$. $\hat{\mathbf{H}}=\left(\hat{\mathrm{H}}_{1}, \cdots, \hat{\mathrm{H}}_{\mathrm{k}}, \cdots, \hat{\mathrm{H}}_{\mathrm{N}}\right)^{\mathrm{T}}$ is the estimated channel transfer function vector.

$\mathbf{X}^{\mathrm{T}}$ denotes the transpose of vector $\mathbf{X} . \mathbf{X}=\left(\mathrm{X}_{1}, \cdots, \mathrm{X}_{\mathrm{k}}, \cdots, \mathrm{X}_{\mathrm{N}}\right)^{\mathrm{T}}, \mathbf{W}_{\mathrm{t}}=\left(\mathrm{W}_{\mathrm{t} 1}, \cdots, \mathrm{W}_{\mathrm{tk}}, \cdots, \mathrm{W}_{\mathrm{tN}}\right)^{\mathrm{T}}$, and $\hat{\mathbf{V}}=\left(\hat{\mathrm{V}}_{1}, \cdots, \hat{\mathrm{V}}_{\mathrm{k}}, \cdots, \hat{\mathrm{V}}_{\mathrm{N}}\right)^{\mathrm{T}}$ are transmit signal vector, transmit equalizer weight vector, and virtual noise vector, respectively. At the virtual receiver, the signal passing through the receive equalizer is given as

$$
\hat{\mathbf{Z}}=\hat{\mathbf{W}}_{\mathrm{r}}^{\mathrm{d}} \hat{\mathbf{R}}=\hat{\mathbf{W}}_{\mathrm{r}}^{\mathrm{d}}\left(\hat{\mathbf{H}}^{\mathrm{d}} \mathbf{W}_{\mathrm{t}}^{\mathrm{d}} \mathbf{X}+\hat{\mathbf{V}}\right)
$$

where $\hat{\mathbf{Z}}=\left(\hat{Z}_{1}, \cdots, \hat{Z}_{\mathrm{k}}, \cdots, \hat{Z}_{\mathrm{N}}\right)^{\mathrm{T}} \quad$ and $\quad \hat{\mathbf{W}}_{\mathrm{d}}^{\mathrm{r}}=\operatorname{diag}\{\hat{\mathbf{W}}\} . \quad \hat{\mathbf{W}}_{\mathrm{r}}=\left(\hat{\mathrm{W}}_{\mathrm{r} 1}, \cdots, \hat{\mathrm{W}}_{\mathrm{rk}}, \cdots, \hat{\mathrm{W}}_{\mathrm{rN}}\right)^{\mathrm{T}}$ denotes virtual receive equalizer weight vector. The error function is defined as

$$
\mathrm{E}=\sum_{\mathrm{k}=1}^{\mathrm{N}}\left|\mathrm{e}_{\mathrm{k}}\right|^{2}=\sum_{\mathrm{k}=1}^{\mathrm{N}}\left|\mathrm{X}_{\mathrm{k}}-\hat{\mathrm{Z}}_{\mathrm{k}}\right|^{2}
$$

In Eq.(3), the error signal corresponding to the k-th frequency component is defined as

$$
\mathrm{e}_{\mathrm{k}}=\mathrm{X}_{\mathrm{k}}-\hat{\mathrm{Z}}_{\mathrm{k}}=\mathrm{X}_{\mathrm{k}}-\hat{\mathrm{W}}_{\mathrm{rk}}\left(\hat{\mathrm{H}}_{\mathrm{k}} \mathrm{W}_{\mathrm{rk}} \mathrm{X}_{\mathrm{k}}+\hat{\mathrm{V}}_{\mathrm{k}}\right)
$$


where $\mathrm{X}_{\mathrm{k}}$ and $\hat{\mathrm{V}}_{\mathrm{k}}$ denote the $\mathrm{k}$-th frequency component of transmit signal vector and virtual noise vector, respectively. $\mathrm{H}_{\mathrm{k}}$ is the $\mathrm{k}$-th component of frequency transfer function. $\mathrm{W}_{\mathrm{tk}}$ and $\hat{\mathrm{W}}_{\mathrm{rk}}$ are the k-th weight of transmit equalizer and virtual receive equalizer, respectively.

The objective is to minimize the error function E in Eq.(3). From Eq.(4), frequency-domain square error signal is given as $\left|e_{k}\right|^{2}$. In order to minimize $E$ with respect to both $W_{t k}$ and $\hat{\mathrm{W}}_{\mathrm{rk}}$, derivations of $\left|\mathrm{e}_{\mathrm{k}}\right|^{2}$ with respect to both $\mathrm{W}_{\mathrm{tk}}$ and $\hat{\mathrm{W}}_{\mathrm{rk}}$ are set to be zero. To solve this problem, we employ the following iterative algorithm which simultaneously updates two weight vector $\mathbf{W}_{\mathrm{t}}$ and $\hat{\mathbf{W}}_{\mathrm{r}}$, respectively.

First, we try to find the transmit equalizer weight $\mathrm{W}_{\mathrm{tk}}$ by minimizing the square error of $\left|e_{\mathrm{k}}\right|^{2}$ in Eq.(4) with respect to $W_{\mathrm{tk}}$. The square error signal $e_{\mathrm{k}}$ corresponding to the $\mathrm{k}$-th frequency component is given as

$$
\left|e_{k}\right|^{2}=\left|X_{k}-W_{r k}\left(H_{k} W_{t k} X_{k}+V_{k}\right)\right|^{2}
$$

The derivative of Eq.(4) with respect to $W_{\mathrm{tk}}$ is given as

$$
\nabla_{\mathrm{W}_{\mathrm{tk}}}\left|\mathrm{e}_{\mathrm{k}}\right|^{2}=-2\left(\hat{\mathrm{W}}_{\mathrm{rk}} \hat{\mathrm{H}}_{\mathrm{k}} \mathrm{X}_{\mathrm{k}}\right)^{*} \mathrm{e}_{\mathrm{k}}
$$

where $\nabla_{w}=\frac{\partial}{\partial w_{x}}-j \frac{\partial}{\partial w_{y}},\left(w=w_{x}+j w_{y}\right)$. Thus, the recursive equation for iterative algorithm is obtained as

$$
\mathrm{W}_{\mathrm{tk}}(\mathrm{n}+1)=\mathrm{W}_{\mathrm{tk}}(\mathrm{n})+2 \mu\left(\hat{\mathrm{W}}_{\mathrm{rk}} \hat{\mathrm{H}}_{\mathrm{k}} \mathrm{X}_{\mathrm{k}}\right)^{*} \mathrm{E}
$$

where $\mu$ is step size to adjust convergence speed. By extending the above discussion to the vector expression, we can obtain

$$
\mathbf{W}_{\mathrm{t}}(\mathrm{n}+1)=\mathbf{W}_{\mathrm{t}}(\mathrm{n})+2 \mu\left(\hat{\mathbf{W}}_{\mathrm{r}}^{\mathrm{d}} \hat{\mathbf{H}}^{\mathrm{d}} \mathbf{X}\right)^{*} \mathrm{E}
$$

where the norm of the transmit equalizer weight vector is normalized to a constant value in order to keep the total average transmit power to be constant. Similarly, the receive equalizer weight vector is determined by minimizing the square error of $\mathbf{e}$ in Eq.(4) with respect to $\hat{\mathbf{W}}_{\mathrm{r}}$. The error signal vector is defined as

$$
\mathbf{e}=\mathbf{X}-\hat{\mathbf{W}}_{\mathrm{r}}^{\mathrm{d}} \hat{\mathbf{R}}
$$

where $\hat{\mathbf{R}}=\left(\hat{\mathrm{R}}_{1}, \cdots, \hat{\mathrm{R}}_{\mathrm{k}}, \cdots, \hat{\mathrm{R}}_{\mathrm{N}}\right)^{\mathrm{T}}$ is the receive signal vector at the virtual receiver. Thus, the square error of the $\mathrm{k}$-th component of the error vector is given as

$$
\left|\mathrm{e}_{\mathrm{k}}\right|^{2}=\left|\mathrm{X}_{\mathrm{k}}-\hat{\mathrm{W}}_{\mathrm{rk}} \hat{\mathrm{R}}_{\mathrm{k}}\right|^{2}
$$

By differentiating Eq.(10) with respect to the k-th weight $\hat{W}_{\text {rk }}$, we can obtain

$$
\nabla_{\hat{\mathrm{W}}_{\mathrm{rk}}}\left|\mathrm{e}_{\mathrm{k}}\right|^{2}=-2 \hat{\mathrm{R}}_{\mathrm{k}}^{*} \mathrm{e}_{\mathrm{k}}
$$

Thus, the updating equation for the receive weight vector $\hat{\mathbf{W}}_{\mathrm{r}}$ at the $\mathrm{n}$-th iteration is given as

$$
\mathbf{W}_{\mathrm{r}}(\mathrm{n}+1)=\mathbf{W}_{\mathrm{r}}(\mathrm{n})+2 \mu(\hat{\mathbf{R}})^{*} \mathrm{E}
$$

With the proposed iterative algorithm, transmit and receive equalizer weights $\mathbf{W}_{t}$ and $\hat{\mathbf{W}}_{\mathrm{r}}$ are determined based on recursive equations in Eqs.(8) and (12) until weight vectors are optimized, i.e., the square error of $\mathbf{e}$ is minimized. After optimum weights are determined, 
the signal weighted by $\mathbf{W}_{t}$ is transmitted to radio channel. At the receiver, the receive equalizer weight vector $\hat{\mathbf{W}}_{\mathrm{r}}$ is determined by observing a received pilot sequence.

\subsection{Extension to decision-feedback equalization case}

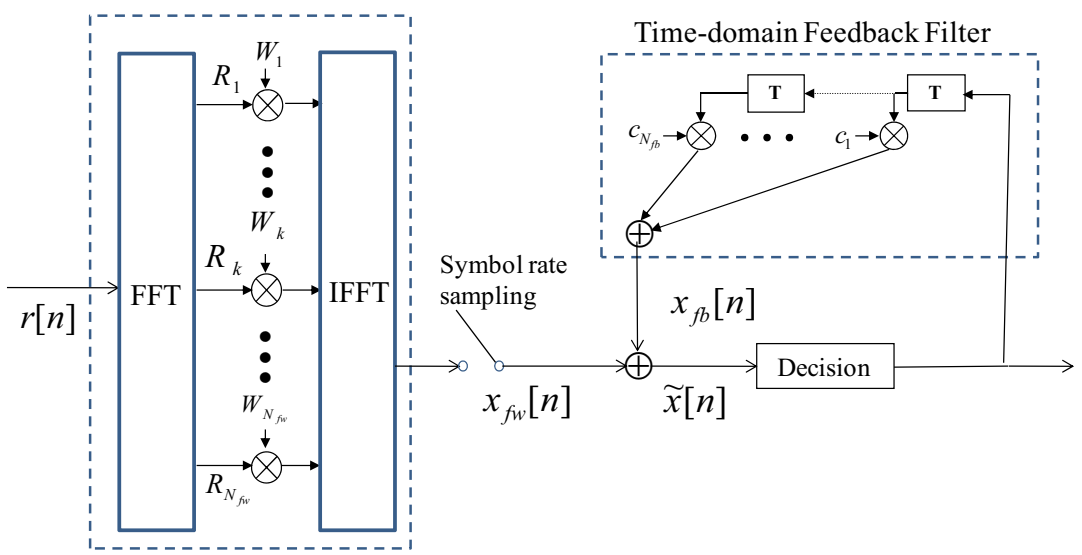

Frequency-domain Feed-forward Filter

Fig. 2. Block diagram of the proposed system with decision feedback equalizer, where virtual channel and virtual receiver are equipped at the transmitter.

Transmitter

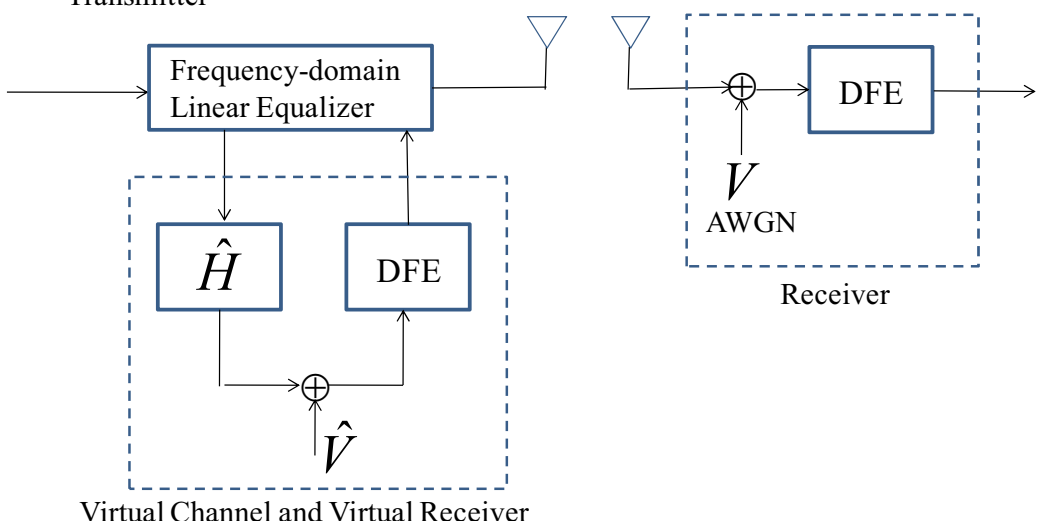

Fig. 3. Decision feedback equalizer with frequency-domain feedforward filter.

The proposed method is extendable to nonlinear equalizers such as decision feedback equalizer (DFE) which offers better equalization performance than linear ones. Block diagram of the system is the same as that in Figure 1 except that DFE is used at both virtual and real receivers. The detailed block diagram of DFE with frequency-domain feed-forward filter and time-domain feedback filter is shown in Figure 3, where $N_{f w}$ and $N_{f b}$ denote the 
number of taps in frequency-domain feed-forward filter and time-domain feedback filter, respectively. $\mathrm{x}_{\mathrm{fw}}[\mathrm{n}]$ and $\mathrm{x}_{\mathrm{fb}}[\mathrm{n}]$ denote the output signals of feed-forward and feedback filters at $\mathrm{n}$-th time instant. $\mathrm{c}_{l}$ is the $l$-th tap coefficient of feedback filter. In Figure 3, DFE output signal for the $\mathrm{n}$-th symbol is given as

$$
\tilde{x}[n]=x_{f w}[n]+x_{f b}[n]
$$

where feedback filter output $\mathrm{x}_{\mathrm{fb}}[\mathrm{n}]$ is expressed as

$$
\mathrm{x}_{\mathrm{fb}}[\mathrm{n}]=\sum_{\mathrm{l}=1}^{\mathrm{N}_{\mathrm{fb}}} \mathrm{c}_{\mathrm{l}} \hat{\mathrm{x}}_{(\mathrm{n}-1)}, \quad\left(\mathrm{n}>\mathrm{N}_{\mathrm{fb}}\right)
$$

where $\hat{x}_{(n-1)}$ denotes the $n-1$ th decided symbol. If a known sequence is used to determine tap coefficients, the decided symbol $\hat{x}_{(n-1)}$ in Eq.(14) is replaced with known symbol $x_{(n-1)}$. Hence, assuming a known training sequence, feedback filter output $\mathrm{x}_{\mathrm{fb}}[\mathrm{n}]$ is expressed as

$$
\mathrm{x}_{\mathrm{fb}}[\mathrm{n}]=\sum_{\mathrm{l}=1}^{\mathrm{N}_{\mathrm{fb}}} \mathrm{c}_{\mathrm{l}} \mathrm{x}_{(\mathrm{n}-1)}, \quad\left(\mathrm{n}>\mathrm{N}_{\mathrm{fb}}\right)
$$

By taking Fourier transform of Eq.(15), we can obtain frequency-domain expression of the feedback filter output; the k-th frequency component of feedback signal is expressed as

$$
\mathrm{x}_{\mathrm{fb}}[\mathrm{n}]=\sum_{\mathrm{l}=1}^{\mathrm{N}_{\mathrm{fb}}} \mathrm{c}_{\mathrm{l}} \mathrm{X}_{\mathrm{k}} \mathrm{e}^{-\mathrm{j} 2 \frac{\mathrm{knl}}{\mathrm{N}}}=\sum_{\mathrm{l}=1}^{\mathrm{N}_{\mathrm{fb}}} \mathrm{c}_{\mathrm{l}} \mathrm{Q}_{\mathrm{k}, \mathrm{l}}, \quad\left(\mathrm{n}>\mathrm{N}_{\mathrm{fb}}\right)
$$

where $\mathrm{Q}_{\mathrm{k}, \mathrm{l}} \equiv \mathrm{X}_{\mathrm{k}} \mathrm{e}^{-\mathrm{j} 2 \frac{\mathrm{kkl}}{N}}$ denote the $\mathrm{k}$-th frequency component of $1 \mathrm{~T}$ time-delayed signal in feedback filter.

To determine optimum weight vectors of transmit and receive equalizers, we calculate the error signal at the virtual receiver. Similarly to the previous discussion, the square error signal corresponding to the $\mathrm{k}$-th frequency component at the virtual receiver is defined as

$$
\left|e_{k}\right|^{2}=\left|X_{k}-\hat{X}_{f w, k}-\hat{X}_{f b, k}\right|^{2}
$$

where the k-th frequency component of the virtual feed-forward filter output $\hat{\mathrm{X}}_{\mathrm{fw}, \mathrm{k}}$ is expressed as

$$
\hat{\mathrm{X}}_{\mathrm{fw}, \mathrm{k}}=\hat{\mathrm{W}}_{\mathrm{rk}} \hat{\mathrm{R}}_{\mathrm{k}}=\hat{\mathrm{W}}_{\mathrm{rk}}\left(\hat{\mathrm{H}}_{\mathrm{k}} \mathrm{W}_{\mathrm{tk}} \mathrm{X}_{\mathrm{k}}+\hat{\mathrm{V}}_{\mathrm{k}}\right)
$$

where $\hat{R}_{k}=\hat{H}_{k} W_{t k} X_{k}+\hat{V}_{k}$ is the k-th frequency component of the received signal at the virtual receiver. The derivative of Eq.(18) with respect to $W_{t k}$ is given as

$$
\nabla_{\mathrm{W}_{\mathrm{tk}}}\left|\mathrm{e}_{\mathrm{k}}\right|^{2}=2\left(\hat{\mathrm{W}}_{\mathrm{rk}} \hat{\mathrm{H}}_{\mathrm{k}} \mathrm{X}_{\mathrm{k}}\right)^{*} \mathrm{e}_{\mathrm{k}}
$$

Thus, the recursive equation for iterative algorithm is given as

$$
\mathrm{W}_{\mathrm{tk}}(\mathrm{n}+1)=\mathrm{W}_{\mathrm{tk}}(\mathrm{n})+2 \mu\left(\hat{\mathrm{W}}_{\mathrm{rk}} \hat{\mathrm{H}}_{\mathrm{k}} \mathrm{X}_{\mathrm{k}}\right)^{*} \mathrm{E}
$$

Similarly, the recursive equations for $\hat{W}_{\mathrm{rk}}$ and $\hat{c}_{1}$ are obtained by taking derivative of Eq.(17) with respect to $\hat{W}_{\mathrm{rk}}$ and $\hat{\mathrm{c}}_{1}$, respectively;

$$
\begin{gathered}
\hat{\mathrm{W}}_{\mathrm{rk}}(\mathrm{n}+1)=\hat{\mathrm{W}}_{\mathrm{rk}}(\mathrm{n})+2 \mu\left(\hat{\mathrm{R}}_{\mathrm{k}}\right)^{*} \mathrm{E} \\
\hat{\mathrm{c}}_{\mathrm{l}}(\mathrm{n}+1)=\hat{\mathrm{c}}_{\mathrm{l}}(\mathrm{n})+2 \mu\left(\hat{\mathrm{Q}}_{\mathrm{l}}\right)^{*} \mathbf{e}
\end{gathered}
$$


where $\hat{\mathrm{Q}}_{1}=\left(\hat{\mathrm{Q}}_{11}, \cdots, \hat{\mathrm{Q}}_{\mathrm{lk}}, \cdots, \hat{\mathrm{Q}}_{\mathrm{IN}}\right)$ is the frequency-domain vector expression of IT timedelayed feedback signal, $\mathbf{e}=\left(\mathrm{e}_{1}, \cdots, \mathrm{e}_{\mathrm{k}}, \cdots, \mathrm{e}_{\mathrm{N}}\right)^{\mathrm{T}}$ is the error signal vector, and $\mu$ is a step size. By extending the above equations to the vector expression, we can obtain

$$
\begin{gathered}
\mathbf{W}_{\mathrm{t}}(\mathrm{n}+1)=\mathbf{W}_{\mathrm{t}}(\mathrm{n})+2 \mu\left(\hat{\mathbf{W}}_{\mathrm{r}}^{\mathrm{d}} \hat{\mathbf{H}}^{\mathrm{d}} \mathbf{X}\right)^{*} \mathrm{E} \\
\mathbf{W}_{\mathrm{r}}(\mathrm{n}+1)=\mathbf{W}_{\mathrm{r}}(\mathrm{n})+2 \mu(\hat{\mathbf{R}})^{*} \mathrm{E} \\
\hat{\mathbf{c}}(\mathrm{n}+1)=\hat{\mathbf{c}}(\mathrm{n})+2 \mu(\hat{\mathbf{Q}})^{*} \mathbf{e}
\end{gathered}
$$

where $\hat{\mathbf{c}}=\left(\hat{\mathrm{c}}_{1}, \cdots, \hat{\mathrm{c}}_{\mathrm{k}}, \cdots, \hat{\mathrm{c}}_{\mathrm{N}_{\mathrm{fb}}}\right)$ denotes the feedback tap vector of virtual DFE and $\hat{\mathbf{Q}}=\left(\hat{\mathbf{Q}}_{1}, \cdots, \hat{\mathbf{Q}}_{\mathrm{k}}, \cdots, \hat{\mathbf{Q}}_{\mathrm{N}_{\mathrm{fb}}}\right)^{\mathrm{T}}$ denotes the feedback signal matrix of virtual DFE.

\section{Performance evaluation}

Performance of a SC system using transmit/receive equalization is evaluated by computer simulation. System block diagram is the same as that in Figure 1. QPSK modulation is adopted. A square root of raised cosine filtering with a roll-off factor of $\alpha=0.2$ is employed. Propagation model is attenuated 6-path quasistatic Rayleigh fading. Block length for FDE is set to 128 symbols. Guard interval whose length is 16 symbols is inserted into every blocks to eliminate inter-block interference. Additive white Gaussian noise (AWGN) is added at the receiver. For simplicity, it is assumed that frequency channel transfer function is known to both transmitter and the receiver. Transmit/receive equalizer weights are determined with least mean square (LMS) algorithm, where sufficient number of training symbols is assumed for simplicity.

In this study, we also evaluate BER performance of vector coding (VC) transmission in SISO channel. The basic concept of VC is the same as that of E-SDM in MIMO system; eigenvectors of channel autocorrelation matrix is used for weight matrices of transmit and receive filters. Therefore, data streams are transmitted through multiple eigenpath channels between transmit and receive filters. To minimize the average BER in VC system, adaptive bit and power loading based on BER minimization criterion is adopted; the bit allocation pattern which minimize the average BER is selected among possible bit allocation patterns under constraint of a constant transmit power and a constant data rate, where modulation scheme is selected among QPSK, 16QAM, and 64QAM according to each eigenpath channel condition. Consequently, provided that CSI is known to the transmitter, the minimum average BER in SISO channel is achieved by VC transmission with adaptive bit and power loading.

Figure 4 shows BER performance of the SC system using the proposed method in attenuated 6-path quasistatic Rayleigh fading, where normalized delay spread values of $\tau / \mathrm{T}$ are $\tau / T=0.769$ and 2.69 for Figs(a) and (b), respectively. $T$ is symbol duration. DFE is employed for both the proposed and conventional systems, where the number of feedback taps in DFE is set to 3. For comparison purpose, BER performance of the SC system using the conventional receive FDE with and without decision-feedback filter is also shown. BER performance of VC with adaptive bit and power loading is also shown. In Figure 4, in case of linear transmit/receive equalization (i.e., without decision-feedback filter), BER 
performance of the SC systems using the proposed method is improved by about $2.7 \mathrm{~dB}$ at $\mathrm{BER}=10^{-3}$ compared to the case of the conventional receive FDE.

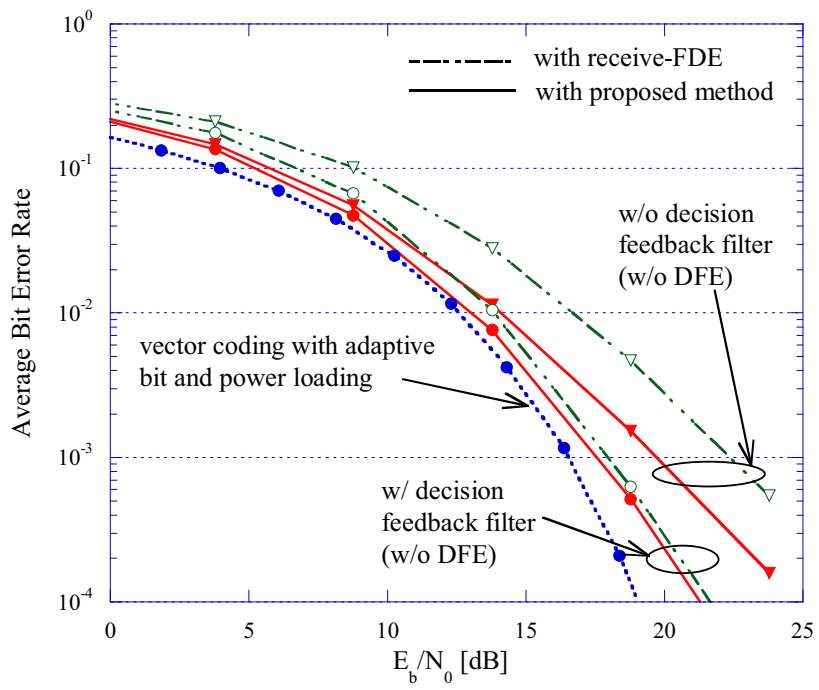

(a) $\tau / \mathrm{T}=0.769$

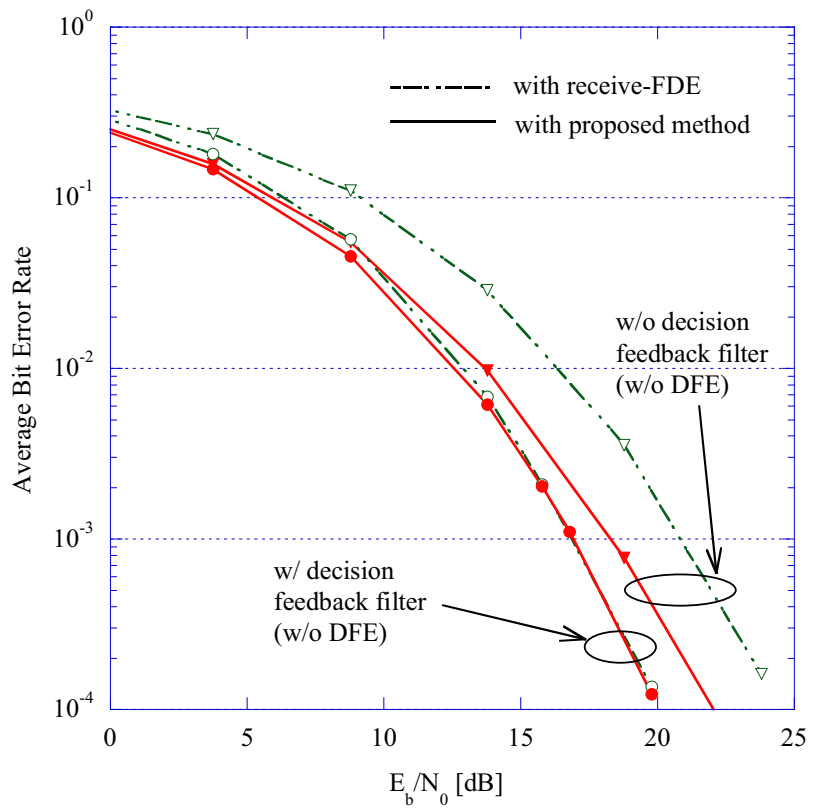

(b) $\tau / T=2.69$

Fig. 4. BER performance of the SC system using the proposed method as a function of $\mathrm{E}_{\mathrm{b}} / \mathrm{N}_{0}$, where normalized delay spread values in figures $(a)$ and $(b)$ are $\tau / T=0.769$ and $\tau / T=2.69$. 


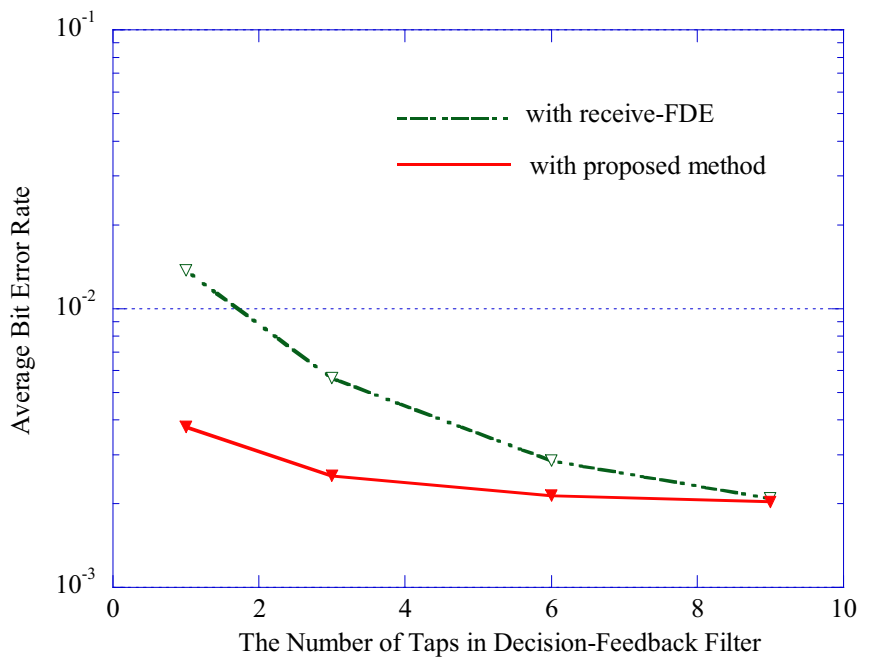

Fig. 5. BER performance of the SC system using the proposed method as a function of the number of feedback taps in decision-feedback filter, where $E_{b} / N_{0}=15.8 \mathrm{~dB}$ and normalized delay spread is $\tau / T=2.69$.

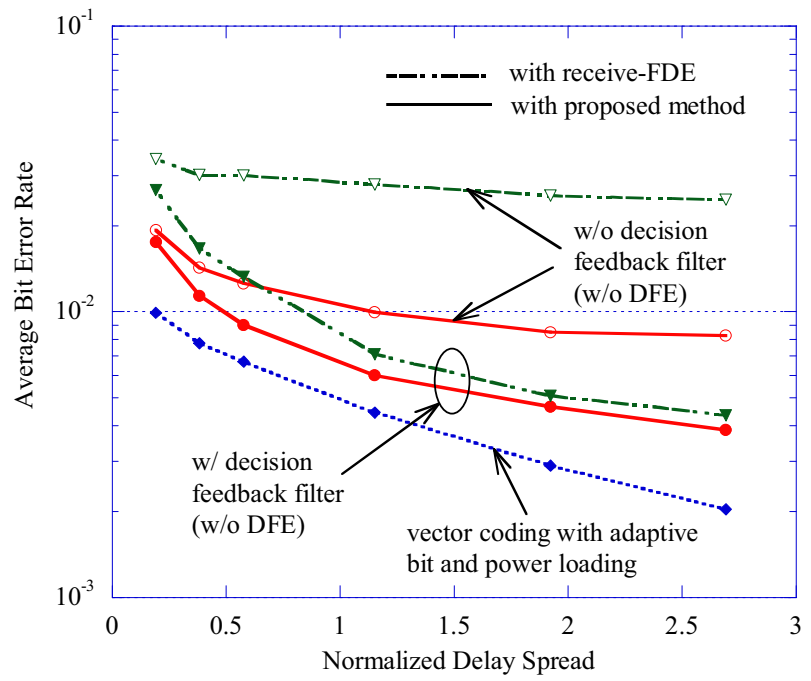

Fig. 6. BER performance of the SC system using the proposed method as a function of normalized delay spread, where $\mathrm{E}_{\mathrm{b}} / \mathrm{N}_{0}$ is set to $13.8 \mathrm{~dB}$.

When decision-feedback filter is adopted in both systems, the proposed system achieves better BER performance than case using the conventional one in lower $\mathrm{E}_{\mathrm{b}} / \mathrm{N}_{0}$ region. On the other hand, in higher $\mathrm{E}_{\mathrm{b}} / \mathrm{N}_{0}$ region, it can be seen that BER performance of the proposed 
system becomes close to that of the conventional one as $\mathrm{E}_{\mathrm{b}} / \mathrm{N}_{0}$ increases. In addition, it can be seen that difference between the proposed method and $\mathrm{VC}$ with adaptive bit and power loading in BER performance is about $2.3 \mathrm{~dB}$ at $\mathrm{BER}=10^{-4}$.

Figure 5 shows BER performance of the proposed and conventional SC systems with decision-feedback filter as a function of the number of feedback taps $\mathrm{N}_{\mathrm{fb}}$, where $\mathrm{E}_{\mathrm{b}} / \mathrm{N}_{0}=15.8 \mathrm{~dB}$ and normalized delay spread $\tau / \mathrm{T}$ is 2.69 . The maximum delay time difference between the first path and last path is set to 8.75T. In general, the required number of taps in decision feedback filter is 9 to suppress intersymbol interference. In Figure 5, both the proposed and conventional systems achieves almost the same BER performance when $\mathrm{N}_{\mathrm{fb}}$ is set to 9 , because the number of feedback taps $\mathrm{N}_{\mathrm{fb}}=9$ is sufficient for suppressing ISI. From this figure, when the number of feedback taps $\mathrm{N}_{\mathrm{fb}}$ is less than 9 taps, it can be seen that the proposed system achieves better BER performance than the conventional system using the receive FDE. This result means that the required number of feedback taps in the proposed system is less than that in the conventional one.

Figure 6 shows BER performance of the SC systems using the proposed method as a function of normalized delay spread, where $E_{b} / N_{0}=13.8 \mathrm{~dB}$ is assumed. BER performance of the SC systems using the conventional receive equalization with and without decisionfeedback filter is also shown. For case with DFE, the sufficient number of feedback taps is used for various delay spread channel. From this figure, it can be seen that the SC system with transmit/receive DFE with decision-feedback filter using the proposed algorithm achieves better BER performance than those using the receive FDE for various delay spread conditions.

\section{Conclusion}

An iterative optimization method of transmit/receive frequency domain equalization (FDE) was proposed for single carrier transmission systems, where both transmit and receive FDE weights are iteratively determined with a recursive algorithm so as to minimize the error signal at a virtual receiver. With computer simulation, it is confirmed that the proposed transmit/receive equalization method achieves better BER performance than that of the system using the conventional ones.

\section{References}

D. Falconer; S. L. Ariyavisitakul; A.Benyamin-Seeyar \& B. Eidson (2002). Frequency Domain Equalization for Single Carrier Broadband Wireless Systems, IEEE Commun. Magazine, pp. 58-66.

F. Adachi; D. Garg; S. Takaoka \& K. Takeda (2005). Broadband CDMA Technique, IEEE Wireless Communications, no. 4, pp. 8-18.

IEEE Std 802.16e/D9 (2005). Air Interface for Fixed and Mobile Broadband Wireless Access Systems.

J. Chuang and N. Sollenberger, Beyond 3G (2000): wideband wireless data access based on OFDM and dynamic packet assignment, IEEE Commun. Mag., vol. 38, no. 7, pp. 78-87.

K. Ban, et al. (2000), Joint optimization of transmitter/receiver with multiple transmit/receive antennas in band-limited channels, IEICE Trans. Commun., vol. E83-B, no. 8, pp. 16971703. 
S. Kasturia (1990), Vector coding for partial response channels, IEEE Trans. Infor. Theory, vol. 36, no. 4 .

R. van Nee \& R. Prasad, OFDM for wireless multimedia communications, Artech House

Y. Akaiwa, Introduction to digital mobile communication, John Wiley \& Sons, Inc. 


\section{Mobile and Wireless Communications Physical Layer Development and Implementatiom}

Edited by Salma Ait Fares and Fumiyuki Adachi

ISBN 978-953-307-043-8

Hard cover, 290 pages

Publisher InTech

Published online 01, January, 2010

Published in print edition January, 2010

Mobile and Wireless Communications have been one of the major revolutions of the late twentieth century. We are witnessing a very fast growth in these technologies where mobile and wireless communications have become so ubiquitous in our society and indispensable for our daily lives. The relentless demand for higher data rates with better quality of services to comply with state-of-the art applications has revolutionized the wireless communication field and led to the emergence of new technologies such as Bluetooth, WiFi, Wimax, Ultra wideband, OFDMA. Moreover, the market tendency confirms that this revolution is not ready to stop in the foreseen future. Mobile and wireless communications applications cover diverse areas including entertainment, industrialist, biomedical, medicine, safety and security, and others, which definitely are improving our daily life. Wireless communication network is a multidisciplinary field addressing different aspects raging from theoretical analysis, system architecture design, and hardware and software implementations. While different new applications are requiring higher data rates and better quality of service and prolonging the mobile battery life, new development and advanced research studies and systems and circuits designs are necessary to keep pace with the market requirements. This book covers the most advanced research and development topics in mobile and wireless communication networks. It is divided into two parts with a total of thirty-four stand-alone chapters covering various areas of wireless communications of special topics including: physical layer and network layer, access methods and scheduling, techniques and technologies, antenna and amplifier design, integrated circuit design, applications and systems. These chapters present advanced novel and cutting-edge results and development related to wireless communication offering the readers the opportunity to enrich their knowledge in specific topics as well as to explore the whole field of rapidly emerging mobile and wireless networks. We hope that this book will be useful for students, researchers and practitioners in their research studies.

\section{How to reference}

In order to correctly reference this scholarly work, feel free to copy and paste the following:

Xiaogeng Yuan, Osamu Muta and Yoshihiko Akaiwa (2010). Iterative Joint Optimization of Transmit/Receive Frequency-Domain Equalization in Single Carrier Wireless Communication Systems, Mobile and Wireless Communications Physical Layer Development and Implementatiom, Salma Ait Fares and Fumiyuki Adachi (Ed.), ISBN: 978-953-307-043-8, InTech, Available from: http://www.intechopen.com/books/mobile-andwireless-communications-physical-layer-development-and-implementatiom/iterative-joint-optimization-oftransmit-receive-frequency-domain-equalization-in-single-carrier-wir

\section{INTECH}

open science | open minds 


\section{InTech Europe}

University Campus STeP Ri

Slavka Krautzeka 83/A

51000 Rijeka, Croatia

Phone: +385 (51) 770447

Fax: +385 (51) 686166

www.intechopen.com

\section{InTech China}

Unit 405, Office Block, Hotel Equatorial Shanghai

No.65, Yan An Road (West), Shanghai, 200040, China

中国上海市延安西路65号上海国际贵都大饭店办公楼405单元

Phone: +86-21-62489820

Fax: +86-21-62489821 
(C) 2010 The Author(s). Licensee IntechOpen. This chapter is distributed under the terms of the Creative Commons Attribution-NonCommercial-ShareAlike-3.0 License, which permits use, distribution and reproduction for non-commercial purposes, provided the original is properly cited and derivative works building on this content are distributed under the same license. 